\title{
On the Birth and Growth of Concepts
}

\author{
Jean M. Mandler
}

This article describes what the earliest concepts are like and presents a theory of the spatial primitives from which they are formed. The earliest concepts tend to be global, like animal and container, and it is hypothesized that they consist of simplified redescriptions of innately salient spatial information. These redescriptions become associated with sensory and other bodily experiences that are not themselves redescribed, but that enrich conceptual thought. The initial conceptual base becomes expanded through subdivision, sometimes aided by language that points up these divisions or suggests new spatial analyses, and by the analogical extension of spatially derived concepts to nonspatial domains. This formulation is contrasted with Fodor's (1998) metaphysical theory of concept formation.

Keywords: Concept Formation; Infant Concepts; Innate Primitives; Perceptual Meaning Analysis; Spatial Representations

In this article I discuss what the earliest concepts are like, describe a theory of the primitives from which they are formed, and suggest how concepts become more complex with development. The account here is necessarily somewhat sketchy (more details can be found in Mandler, 2004); for example, it spells out neither the many different ways that psychologists and philosophers define concepts nor the nature of the larger cognitive system that includes them. I believe the system I describe escapes Fodor's (1998) puzzle of how it is possible to learn any concept, but at the same time my use of the term 'concept' perhaps differs from his. I use the term 'concept' to refer to declarative knowledge about object kinds and events that is potentially accessible to conscious thought. A good deal of our knowledge about the world is not

\footnotetext{
Jean Mandler is a Distinguished Research Professor in the Department of Cognitive Science at the University of California, San Diego. Correspondence to: Jean Mandler, Department of Cognitive Science, University of California, San Diego, 9500 Gilman Drive, La Jolla, CA 92093-0515, USA. Email: jmandler@ucsd.edu
} 
conceptual in this sense, but consists of perceptual information that is procedural in nature and does not operate under conceptual descriptions. The hope of solving Fodor's puzzle lies in explicating the relations between the perceptual and conceptual systems. We only partly understand these relations at present, but this article raises some of the pertinent issues, while presenting a theory of the way that concepts can be created out of perceptual processing.

One of the serendipities of infancy research is that a lot of things that seem obvious when you study adults become not so obvious when you study babies. The premise that one must learn a concept by hypothesis formation and test is one of these (Fodor, 1975). Although hypothesis and test is one way for students at university to learn new material, it is a highly implausible method for the newborn opening her eyes for the first time and gazing at the world. Even if we assume a moderate amount of innate machinery, newborns seem unlikely to have the wherewithal to engage in hypothesis and test. So some time ago I parted company with Fodor on what concept formation involves, insofar as he assumed that hypothesis and test is the only conceivable rational model, where irrational consists of being hit over the head (Fodor, 1975).

Ultimately, even Fodor found this view of concept formation indefensible, because to hypothesize what something is requires one to have a concept of what it is, and so when one hypothesizes that something is a dog, one must already have a concept of dog. His current solution to this quandary (Fodor, 1998) is to relegate the topic of concept formation to metaphysics (one acquires dog by locking onto doginess). But that seems an unnecessary cry of despair. I suspect that many scientists, or at least developmentalists like me who study the origins of concepts, do not accept the premise that led to the quandary-that concept formation must take place by hypothesis and test. In the first instance, it almost certainly does not. Of course, hypothesis and test can be useful: one can use it to limit the breadth of a conceptual generalization-Are all dogs friendly like my pal Fido?-but this is a way of fine-tuning an existing concept, not a method of arriving at $d o g$ in the first place. One can also use hypothesis and test to accept or reject new exemplars of a concept-is that a dog?-but identification of instances is only a part of what concept formation is about. As Frege persuasively argued, reference is not the same as sense, and it is sense (conceptual meaning) and how it arises that I discuss here.

Another aspect of concept formation that was widely accepted before we studied it in infancy was that 'basic-level' concepts ${ }^{1}$ are the first to be formed. But that turns out simply to be wrong, and a good thing too, because the hypothesis made concept acquisition unprincipled and difficult to predict. Instead, the first object concepts tend to be highly global, rather sketchy and abstract, 'superordinate' notions, which not only makes concept acquisition predictable but has far-reaching consequences for the way the mind develops.

The initial global concepts provide the infant with simple definitions that will ground everyday 'basic-level' concepts such as dog and cup (a dog is an animal; a cup is a container). But 'basic-level' concepts are hard-won achievements; they are 
conceptual subdivisions carved out of broader, less detailed concepts. In McDonough's and my lab, we found that between 7 and 11 months (and perhaps starting earlier) infants develop a number of global concepts like animal, furniture, plant, and container (Mandler \& McDonough, 1993, 1998a) but lack many everyday, seemingly simpler, concepts like dog, chair, tree, or cup. Our data strongly suggest that infants in this age range see a dog and interpret it as animal, see a cup and think container. It takes many more months to achieve thinking dog and cup (Mandler \& McDonough, 1998b, 2000).

For example, by 3 months infants can easily learn that dogs and cats look different (for example, after seeing several pictures of dogs they will look longer at a cat; Quinn, Eimas, \& Rosenkrantz, 1993), but it is not for another year that they have learned enough other differences between them to claim that they have differential concepts of dog and cat. Evidence for a conceptualization of both of them merely as animal before this time is shown by their willingness to categorize them together and to substitute one for the other when imitating, but not to categorize them with, or when imitating substitute them for, nonanimals (Mandler \& McDonough, 1996, 1998b). ${ }^{2}$

Imitation provides a way to get preverbal infants to 'label' objects, in the sense of showing us how they interpret or construe them. In a technique we call generalized imitation, we model a simple event, such as giving a little replica of a dog a drink from a cup. But instead of just handing back the objects to the infants for their imitation, we vary the objects provided. For example, if we provide a new dog and a rabbit or a new dog and a bird along with the cup, which animal will infants use for their imitation? If they choose randomly among them, it suggests they have construed the $\operatorname{dog}$ as an animal. If they reject the bird, but choose randomly between the dog and the rabbit, it suggests they construed the dog as a land (or possibly legged) animal. If they only choose the other dog, it suggests they construe the dog as a dog. Systematic use of this technique has shown that 'basic-level' artifact concepts such as cup, pan, bed and so on are not well-established until the middle of the second year, and natural kind concepts such as dog and tree tend to be even later (Mandler \& McDonough, 1998b, 2000). Needless to say, this is long after infants are fully capable of distinguishing these categories on a perceptual basis.

The finding that 'basic-level' concepts are late achievements is interesting in part because exhaustively decomposing these concepts into primitives has proved almost impossible. (This difficulty may be one of the reasons for Fodor's discouragement about concept formation and his conclusion that lexical concepts cannot be composed from primitives but instead are 'atomic'). Decomposing infants' early concepts turns out to be easier, and this suggests that one of the things that we should do is direct our decomposition efforts to the conceptual foundations and then see what further can be accomplished through differentiation, new observations, and analogical learning. One thing is clear, however; dog and cup are neither atomic nor unstructured. They inherit the global properties of the concepts from which they were derived. 


\section{J. M. Mandler}

\section{What Follows from the Global Nature of the First Concepts}

The fact that concept formation is primarily top-down in nature, has a number of consequences for how the conceptual system develops (see also Keil, 1998). I have already mentioned one: 'Basic-level' concepts inherit the properties of the global classes from which they are derived. The top-down nature of the process results in a hierarchically organized object conceptual system. Because infants at first divide the world of objects into animals and nonanimals and because learning takes place within existing knowledge structures, every time a new category is learned within these global domains, it is necessarily learned as a subdivision of this larger division. The infant looking at dogs and cats does not at first conceptualize them as two different kinds, but as discussed below, most likely as two different-looking, self-moving interactors. When they do become conceptually distinct, it is as two self-moving interactors that vary in appearance and the sounds they make, that behave rather differently to petting them, and that have different names, but their animal membership is never in question. This membership is so fundamental that it is the last to be lost in cases of semantic dementia and other degenerative diseases; even when patients no longer know the difference between dogs and cats, they still regard both as animals (Hodges, Graham, \& Patterson, 1995).

A serendipitous side effect of top-down differentiation is that it alleviates many definitional problems. It is really difficult to define $d o g$, not only for infants but for adults as well. Among other things, dog needs a physical description that is usually beyond our descriptive powers, but without such a description the definition tends to reduce to an enumeration of various facts about dogs, none of which is crucial. It is considerably easier to provide a good lay definition of global concepts such as animal or nonanimal. ${ }^{3}$

Second, global concepts such as animal or vehicle do not (indeed, cannot) include physical features such as overall shape or parts such as legs, wings, or wheels. This means that the early conceptual categorization of objects is clearly separate from the finer-grained, more detailed perceptual categories that are being formed at the same time and that let infants recognize people and other animals, cars and motorcycles, and so on, even when they conceive of them in a very general way. As we will see, consideration of separate but interacting perceptual and conceptual processes is crucial to solving Fodor's puzzle of how it is possible to learn concepts. People encode a great deal of perceptual and motor information, much of which may not be conceptualized but becomes linked to conceptual representations.

Third, the higher-order conceptual descriptions determine what will be associated with new exemplars, even though the behavior in question may not be observed with them. If a dog, for example, is interpreted as an animal, then observed behaviors of dogs such as sleeping or eating bones become associated not just with dogs but with animals as a class and hence, will at first be generalized to fish and birds (Mandler \& McDonough, 1998b, 2000). Such generalization seems on the surface to be an inferential process (and I have so termed it), but at least at the early stages of concept formation it is almost certainly not hypothesis and test but an associative process that 
enriches the original concept animal with new properties such as sleeping and eating. This associative process can lead to errors (which may be partly responsible for later adopting genuinely inductive strategies where hypothesis and test become relevant), but on the whole it is an efficient method of rapid knowledge acquisition that helps expand the initial conceptual system.

\section{How the First Concepts are Formed}

As best as I can tell from current evidence, early global concepts are all composed from one or more pieces of spatial information, especially movements in space. I call these components conceptual primitives. ${ }^{4}$ An aspect of these primitives that is surprising to some people is that they have structure. For example, one such primitive is container which, as Lakoff (1987) pointed out, requires a bounded space with an inside and an outside. The primitive is structured, because you cannot have an inside without an outside; it is the structure itself that gives the parts meaning. Another example is a linked paths primitive, which consists of objects moving together in conjoint fashion. The reader will note that this notion of primitives is different from the traditional view that primitives must be unstructured particles that cannot be further analyzed. As I use the term, conceptual primitives refer to aspects of space that are used to form concepts. Although their structure can be dissected with respect to space, they are primitive with respect to the conceptual system.

Unlike container, which is both a primitive and an early concept, most concepts consist of more than one primitive. This means that there are few simple concepts in the infant's repertoire. The most common unstructured (atomic) concepts are sensory ones such as red, and these are late acquisitions - children are often as old as 2-3 years before they make conceptual headway in the color domain. It is even possible that concepts involving unstructured sensory information require language in order to be constructed (Roberson, Davidoff, Davies, \& Shapiro, 2005); before then colors, and sounds such as barking, are apt to be unanalyzed perceptual information. They often remain that way-the concepts consisting merely of words pointing to perceptual experiences that are at best only partially analyzed.

Infants are responsive to spatial information and are particularly attracted to moving objects (Arterberry, Craton, \& Yonas, 1993; Kellman, 1993). This begins before they have enough foveal information to differentiate objects on the basis of their physical appearance. This attention to paths of motion may be due to the way the visual system develops or to a broader tendency to attend to events in the world. In either case, young infants not only take in spatial information, they pay more attention to it than to what objects look like (e.g., Bahrick, Gogate, \& Ruiz, 2002). They attend to whether objects start moving by themselves, whether they interact with other objects, and the kinds of paths they take.

Of course, over the first few months infants also form perceptual schemas of objects, so that dogs and chairs and so forth become familiar objects to them. However, perceptual schema formation is implicit learning of similarities that 


\section{J. M. Mandler}

requires neither attention nor awareness. For example, pictures or words that have been masked so that they are not visible nevertheless prime stimuli seen later (Bar \& Biederman, 1998; Mandler, Nakamura, \& van Zandt, 1987) and can be discriminated from stimuli not previously presented (Cleary \& Greene, 2005). Responding to something as having been seen before, as shown by smiling or appropriate behavior, is not the same as conceptualizing it. This was one of Piaget's important insights. Infants live in a rich perceptual world that generates a sense of familiarity as they interact with objects and categorize similar appearing things, but that tells us little about whether or how they conceptualize what they are categorizing.

I have proposed that attentional processes are required to form the first concepts, by finding patterns in perceptual data and redescribing (reformatting) them (Mandler, 2004). Initially, redescription is done via the conceptual primitives that are the vocabulary of the mechanism (called Perceptual Meaning Analysis) that does the reformatting. This mechanism is an attentive process that extracts spatial information from perceptual displays and while retaining its analog character recodes it into a skeletal (somewhat topological-like) form. For example, the infant attends to an apple being put into a bowl, but Perceptual Meaning Analysis outputs something like thing into container. Redescriptions like this enable the concept formation that makes conscious thought possible.

A great deal of perceptual information is taken in parallel and most of it is processed outside of awareness. Perceptual information must be reduced and recoded if we are to use it in the limited system that is conscious conceptualization. However, this is not a selective process that extracts bits and pieces of perceptual information while leaving them untouched. In this, we have gone beyond the old empiricist notion that primitive concepts (simple ideas) are merely copies of sensory impressions; rather, they require redescriptive processing. We have no reason to think that conceptual descriptions are the same as perceptual encoding, nor that the perceptual system of the newborn applies conceptual descriptions to the information it takes in.

For example, six-month-olds perceptually categorize faces as male or female (Fagan \& Singer, 1979). Since even adults cannot describe what the difference is, it seems improbable that this discrimination requires a conceptual description. We can look at faces countless times without attending to their details. Perception does not require any conceptual description, let alone an accurate one. It was not until a boring seminar some years ago that I first noticed that eyes and ears were roughly at the same level in a face. Before that I thought eyes were above the ears. Someone once said to me, but how could you think that? You could not wear glasses if the eyes are above the ears. But I did not wear glasses and that was the concept I had; it is how I would describe a face to you (and also why my drawings of faces were childlike). At the same time, I would have been startled to see a face whose eyes actually were above the ears; my face schema represented more veridical information than my concept of a face.

This point is so obvious it may seem trivial. We all know that our concept of a face is poverty-stricken compared to our exquisite ability to differentiate thousands 
of faces. But the implications of this phenomenon are important. We have excellent perceptual information about what faces look like, but greatly simplified and often distorted conceptualizations of them. Perceptual Meaning Analysis lets us think about faces, but it is limited not only by what has been attended to but also by the vocabulary it has at its disposal to represent something conceptually.

Because Perceptual Meaning Analysis is a descriptive mechanism and not a triggering device (or what Fodor would call a brute-causal mechanism), it requires a vocabulary in which to couch its descriptions. As adults, we have a verbal vocabulary we can use to describe new analyses, as I did when I analyzed that eyes and ears are on the same level. But newborns do not, so they need some other representational form to couch the descriptions the analytic mechanism produces. I have suggested (Mandler, 1992, 2004) that image-schemas, which are analog, often kinetic, representations that summarize spatial relations and especially movements in space, provide a sensible and attractive format for the kinds of spatial descriptions that the primitives consist of. However, although this type of representation has much to recommend it in terms of understanding preverbal concepts, as well as analogical thought and imagination in general (Fauconnier, 1994; Fauconnier \& Turner, 2002), it is not crucial for understanding the genesis of concepts out of spatial information. For that, it is the analytic mechanism and what it is sensitive to that matters, whether it outputs image-schemas, perceptual symbols (Barsalou, 1999), or another neurally plausible code.

This level of representation is not itself conscious. The only way I know to bring accessible information into conscious thought is via language or imagery, and for a nonverbal creature there is only imagery. But imagery itself is dependent on underlying knowledge representations. It makes a great deal of sense, therefore, that the underlying representations are something like image-schemas that can both represent concepts and form the basis for imagery, which of course is conscious. Laurence and Margolis (1999) suggested that this is a recidivistic view that relies on a resemblance theory of concepts, but not only did they trivialize my arguments (for example, by taking a diagram as a literal representation of an image-schema), they failed to recognize the crucial difference between imagery and image-schemas. The arguments of the 1970s and 1980s against imagistic representations that resemble their referents are out of date. Image-schemas are analog and often kinetic representations, but like topological representations they consist of only certain kinds of spatial information, and furthermore are not conscious as images are. Clearly, how concepts are represented in the mind is not available to consciousness. If they were, there would be less to argue about.

Because attention is the prerequisite for Perceptual Meaning Analysis, we need to look for perceptual saliencies that attract the newborn's attention. As mentioned earlier, an important example of these is the tendency to attend to paths of motion through space. In addition, a few spatial relations such as containment and contact also seem to attract attention. I suggest that these are the kinds of information that will first be analyzed and thus will underlie the first concepts. So what is needed is a specification of the primitive vocabulary that Perceptual Meaning Analysis uses to 


\section{J. M. Mandler}

redescribe these sorts of spatial information. In what follows, I use capitalization to indicate primitives.

\section{The Spatial Primitives Underlying the First Concepts}

How many innate spatial primitives need there be? As best as I can tell, not all that many redescriptions are needed to get the conceptual system up and running. A few may be given by the perceptual system directly; that is, the perceptual and conceptual systems may use roughly the same vocabulary so redescription is not necessary. This might be the case for THING and MOTION; however, I treat them here as redescriptions. In addition to these, it seems that only a few primitives are needed to arrive at initial concepts of animal and nonanimal. Animals can be described as things that start motion by themselves (that is, without contact with other objects) and interact with other objects, including from a distance. This definition of animal as a self-moving interactor is not a bad core definition of the concept, and it is one that lasts for a lifetime. It is a description that potentially can occur at any time after birth, since it does not require information about the physical appearance of objects, only information about how they move. A similar set of primitive notions achieves nonanimal things that do not start themselves, that may not move at all, but if they do they begin motion only with contact, and that do not interact with other objects (i.e., they may contact other objects but do not engage in interactions).

Table 1 lists these primitives using image-schema terminology (Mandler, 1992, 2004). PATH refers to any object's motion through space, without regard to speed, direction, or shape of either object or path. $\pm \mathrm{PATH}$ is meant to convey that some objects may not move at all. START + CONTACT refers to a path beginning when an object is contacted by another. START + NO CONTACT refers to an object starting to move without contact with another object (i.e., self-starting). Infants have learned this aspect of animals' motion at least by 7 months of age (Pauen, 2000; Poulin, Lepage, \& Ferland, 1996; Spelke, Philips, \& Woodward, 1995). Interaction between objects is expressed by LINK, representing a category of interactions, such as linked

Table 1. Example of decomposition of two concepts into primitives

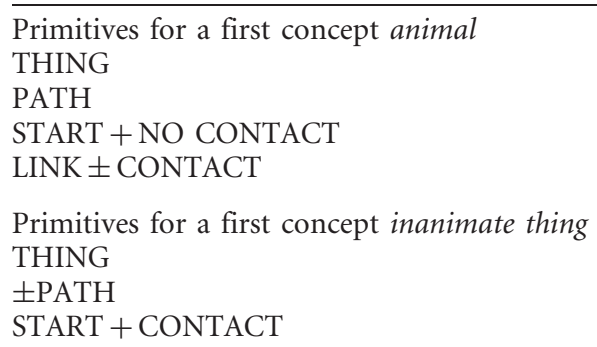


paths, as when two objects follow a common path or 'chase' each other, or back and forth interactions, as in turn-taking (Mandler, 1992). Infants begin to treat objects that interact with them in a contingent fashion as animates at least from 2-3 months of age-for example, they smile at them (Frye, Rawling, Moore, \& Myers, 1983; Murray \& Trevarthen, 1985; Watson, 1972). The temporal element in interactions such as turn-taking is, of course, not itself spatial. Although responsivity to temporal contingencies is innate, as far as conceptualizing them is concerned, turn-taking can be described spatially by kinetic image-schemas and is thought of in spatial terms, such as back and forth. This issue is discussed further below. In contrast, although nonanimals may contact each other and movement may result, they do not interact.

In previous writing, I also posited animate and inanimate motion primitives. I have come to think that although young infants are responsive to information about the shape of paths (e.g., Arterberry \& Bornstein, 2001), this kind of information may not be used for conceptual thought. Even as adults, we are put hard to specify what it is that makes motion seem animate (rhythmical? curvilinear?) or inanimate (straight? unvarying?). This aspect of object paths may be better understood as perceptual information that becomes associated with animal or inanimate thing and that enables infants to identify something as an animal or not, rather than itself being represented by a spatial redescription. How such associative processes might combine with spatial redescriptions is discussed below.

To summarize, a cluster of abstract notions describe animals as things that start themselves and interact with other objects even from a distance. Another cluster describes nonanimals as things that do not start themselves and do not interact. These clusters of meaning creates the overall structuring of the animal and nonanimal domains that organizes and guides infants' concept formation. The learning mechanism that associates these characteristics with each other is not domain-specific; rather it is the kind of process that creates domains such as animate and inanimate things. ${ }^{5}$ (Although the redescriptions may not require learning, bundling them together does.) Rogers and McClelland (2004), although using traditional semantic properties rather than the spatial primitives discussed here, show how a simple but general algorithm can learn patterns that make animals different from plants, and then learn to differentiate kinds within these domains. (A slightly more complex model, for example, one that differentially weights input according to saliency, might avoid the kind of random errors in early learning that such connectionist models, but not infants, display). ${ }^{6}$

The reader may have noted that in characterizing inanimate objects as requiring contact with another object to begin motion, I did not mention causality. We know that infants perceptually differentiate self-starting from starting with contact at least by 6 months of age (Leslie, 1982), but it is uncertain what further is needed in terms of conceptual primitives to jump-start a concept of cause. A likely candidate is transfer of motion from one object to another. Pace Hume's belief that we cannot see causality, there is evidence that we can, or at least we see one of the major components of a commonly experienced causal relation, namely, the transfer of motion from one moving object to another. White (1988) proposed that the 
powerful sense of causality perceived when, say, a billiard ball strikes another, comes from the short duration of iconic storage (about $250 \mathrm{msec}$ ). The iconic store is a large-capacity sensory store that holds visual information prior to attentive processing; it is continuously refreshed, enabling the temporal integration, which makes us see motion as continuous. Michotte (1963) showed that the timing of the launching events in which one billiard ball hits another is crucial for our illusion that we see one ball 'make' the other move. We see a causal relation when a conflict exists between two types of continuity cues. Spatial discontinuity between two objects says there are two objects, whereas continuous motion suggests there is only one. The conflict is resolved by perceiving the causal sequence as the transfer of motion from one object to the other (Michotte called this 'ampliation'). The causal perception disappears when the temporal parameters of the movement do not fall within the time frame of temporal integration (see Mandler, 1998, for more detail).

Of course, there is more to an adult concept of cause than one object launching another. However, as Leslie showed, infants are attuned to contact versus no contact between moving objects, and this is a situation ripe for Perceptual Meaning Analysis. I suggest that what I previously termed a primitive of CAUSED MOTION (Mandler, 1992) is better characterized as a conceptual primitive of MOTION TRANSFER that is the basis of infants' early interpretation of physical causal events. A first concept of cause may not yet involve any notion of force or pressure. Analysis of feelings of force, like other bodily feelings, would almost certainly occur later than the spatial analyses described here. However, as discussed below, feelings of force may not need to be analyzed to get linked up with a spatial MOTION TRANSFER primitive.

Even if there is no force primitive, there is a spatial notion of a path being blocked so that motion stops. When an object runs into an immoveable obstacle, there is no motion transfer to be seen, but an abrupt cessation of motion altogether. Infants as young as 6 months expect that a car running along a track will not pass through a block on the track but will come to a stop (Baillargeon, 1986). Similarly, a concept of tight containment (discussed below) seems to require BLOCKED PATH as a primitive redescription.

An important concept that is in evidence from about 6-9 months is goal, as shown by the work of Woodward (1998) and Csibra and colleagues (Csibra, Biró, Koós, \& Gergely, 2003; Csibra, Gergely, Bíró, Koós, \& Brockbank, 1999; Gergely, Nádasdy, Csibra, \& Bíró, 1995; see also Sodian, Schoeppner, \& Metz, 2004). Infants construe moving animals, and quite likely moving objects in general as goal-directed (see Csibra et al., 2003; Mandler, 2007 for discussion). Woodward (1998) showed that when a person reaches for an object, if a new object is put there and the first object moved to another location, infants as young as 5 months expect the person to reach to the first object rather than continue on the same path as before. Csibra and colleagues showed that by 9 months, infants interpret computer-generated circles following linked paths as goal-directed. By 12 months they do so even when the end of a 'chase' path is not shown. We do not know the details of the first conceptualization of a goal, but it may have to do with interactions at the end of 
a path. The infant might assume that when something, say a hand, goes along a path of motion and then stops and interacts with whatever is at that point, that a goal has been reached. Woodward (1999) showed that sometimes between 5 and 9 months of age, infants discriminate between a hand following a path to an object and grasping it versus following a path and just resting the hand against it. Thus, although I assume that infants understand goal-directed behavior such as chasing in terms of LINKED PATHS, they may use END-OF-PATH + LINK to construct a concept of goal itself.

Turning to subdivisions of the high-level concepts of animal and inanimate thing, work from our lab shows that more limited, although still global, object concepts are being formed during the first year as well. In our culture, vehicle is one of these. I suggest that this concept may at first consist of a combination of a moving (i.e., +PATH) inanimate thing + CONTAINER, although it may include some reference to outdoor things (see below). Note that although various physical characteristics such as size become associated with concepts such as vehicle, they are apparently not part of the initial core concepts themselves. For example, even as late as the third year, children will attempt to put themselves or dolls into objects too small to contain them, suggesting that size may not yet be a fundamental part of the concept (Ware, Uttal, Wetter, \& DeLoache, 2006). Another early (but specific, not global) concept appears to be hand. Leslie (1984) showed that by 4 months of age infants have learned that hands must contact objects to link with them, and as Woodward (1999) showed, infants know the difference between hands that contain versus hands that merely touch. I suggest that the first concept of hand is a recognized body part that both contacts objects and contains them.

Other early global concepts are furniture and plant (Mandler \& McDonough, 1998a). We have not studied these concepts as thoroughly as animals and vehicles. However, we found that seven- to nine-month-olds distinguish furniture from both animals and vehicles, and plants are distinguished from these concepts at 11 months (not studied earlier). Furniture appears to be undifferentiated in this age period; chairs, tables, and beds are not yet conceptual subcategories, although even threemonth-olds can differentiate them perceptually (Behl-Chadha, 1996). More research will be needed to characterize the basis for these concepts. However, I suggest that they may at first be understood in terms of spatial location and -PATH. ${ }^{7}$ Furniture and plants do not move and one is predominantly found indoors and the other outdoors. Even though there are obvious exceptions, it is plausible that infants do not notice them, because they pay less attention to nonmoving objects than to moving ones. We do not have data on the indoor versus outdoor distinction before 16 months, but it seems highly likely to be formed much earlier. Indoors can be conceptualized in terms of CONTAINER (inside a house is contained by walls and ceilings in a way that should be obvious to infants and contrasted with the openness of outside).

Baillargeon and her colleagues (e.g., Baillargeon \& Wang, 2002) have demonstrated that in the first year infants develop increasingly detailed concepts of containment. CONTAINER itself is an important spatial primitive, along with the associated path primitives of INTO and OUT-OF (as well as the resulting states IN and OUT). Other path primitives are associated with surfaces: ONTO and OFF-OF. Two other path 
primitives are UP and DOWN. Location of objects and/or their paths are also encoded and analyzed at some point in the first year. Indeed, the first major subdivision of animal and vehicle (Mandler \& McDonough, 1998a, b), is likely based on their locations: either on the ground (SURFACE) or UP.

There is considerable evidence by now for a progression of increasingly differentiated object concepts in infancy. The work of Baillargeon and her colleagues indicates that relational concepts such as containment and support develop over the course of the first year in the same top-down fashion as do object concepts. Infants begin with simple and broad concepts of spatial relations, using redescriptions such as CONTAINER, IN, CONTACT, ON, OFF, SURFACE, and ATTACHMENT. For example, infants first appear to interpret support as attachment, with something closer to our adult concept, which includes a notion of gravity, coming later. In any case, infants only gradually learn details of support, such as that contact alone is not enough if the surface is vertical, or the amount of horizontal surface that is required (Baillargeon, Kotovsky, \& Needham, 1995). ${ }^{8}$

Similarly, containment does not at first appear to have any quantitative aspects. Although a container must have an opening (Hespos \& Baillargeon, 2001a) anything can fit in a container, large or small (Aguiar \& Baillargeon, 1998; see the discussion of size above). Interestingly, infants learn that a tall object will not disappear completely into a short container, considerably later than they learn the same fact about an object being lowered behind a screen (Hespos \& Bailargeon, 2001b). This difference in pace of learning may be due to differential experience, because infants see more liquids than objects going into containers and more solid objects going behind screens. However, it also suggests that containment is learned independently from behind.

There are also data showing responsiveness to relations per se, rather than to objects exemplifying those relationships. Quinn and colleagues showed this kind of abstract responsiveness to the relations of above and below at 7 months (Quinn, 2003), and we showed that at 9 months infants are responsive to the abstract relations of tight- versus loose-containment (McDonough, Choi, \& Mandler, 2003). Just as for objects, infants in this age range use their foundational primitives to generalize across instances of a relation and react to the relation itself, rather than to specific instances. These data suggest not only that containment itself is conceptualized preverbally, but more than one variety of containment is conceptualized as well. I assume that tight containment is redescribed in terms of CONTAINER + BLOCKED PATH, whereas loose containment is the default case of containment.

The small number of primitives I have mentioned are listed in Table 2. Either singly or in combination they go far toward founding a conceptual system. I assume there are more than those listed here-for example, NEXT-TO, and BETWEEN are likely candidates (see Quinn, Adams, Kennedy, Shettler, \& Wasnik, 2003)—but I do not see why many more will be needed. It may seem surprising, but I believe it is possible to derive the conceptual system of a nine-month-old from somewhere between 20 and 30 spatial primitives. They are all rooted in innate saliences in spatial attention, which set the stage for redescription to take place. 
Table 2. Innate primitives

\begin{tabular}{ll}
\hline Path primitives & \multicolumn{1}{c}{ Other primitives } \\
\hline \pm PATH & THING \\
START-OF-PATH & MOTION \\
END-OF-PATH & MOTION TRANSFER \\
INTO CONTAINER & LINK \\
OUT-OF CONTAINER & CONTAINER \\
ONTO SURFACE & CONTACT \\
OFF-OF SURFACE & SURFACE \\
UP & ATTACHMENT \\
DOWN & \\
BLOCKED PATH & \\
LINKED PATHS & \\
BEHIND? & \\
\hline
\end{tabular}

Note: State primitives derived from path primitives (such as IN) have been omitted

Table 3. Some concepts constructed in the first year from Perceptual Meaning Analysis

\begin{tabular}{|c|c|}
\hline Objects & Relations \\
\hline \multicolumn{2}{|r|}{ Containment } \\
\hline Land (surface) animal & (Going) In \\
\hline Air (up) animal & (Going) Out \\
\hline Vehicle & Tight \\
\hline Land (surface) vehicle & Loose \\
\hline Air (up) vehicle & Taking in (as in eating)? \\
\hline Plant & On \\
\hline \multirow[t]{4}{*}{ Furniture } & Off \\
\hline & Above (Up) \\
\hline & Below (Down) \\
\hline & Behind? \\
\hline Other & Other \\
\hline Hand & Goal \\
\hline Indoor things? & Cause (to move) \\
\hline Outdoor things? & \\
\hline
\end{tabular}

Table 3 provides a list of some concepts constructed from these primitives that current research suggests are achieved by 9-11 months of age and in some cases earlier. ${ }^{9}$ The list is short because this is a relatively new area of research. I am sure there will be a number of similar concepts uncovered. Among other things, everyday action concepts are largely missing from the table. A number of action concepts such as going to bed, drinking or eating, riding in and using keys on vehicles, are implied by our work using generalized imitation, but have not yet been studied in their own right, in the sense that we have not systematically varied them as we have objects. For example, we have evidence that infants understand eating and drinking, but do they 
differentiate the two or the difference between taking in (to the body) and the more general going in?

Whatever the answers to these particular questions, the conceptual system is obviously initially rather simple, but it works in tandem with sensorimotor schemas. Infants do not have to think deep thoughts to recognize people and other animals, to distinguish them from inanimate things, to recognize hands and see that they move objects around. In this, Piaget was correct: a sensorimotor creature without concepts can learn appropriate interactive, recognitory, and adaptive behavior. What he missed was the beginnings of the conceptual system that interprets what is observed and grows at the same time as sensorimotor learning. The conceptual system may be simple at first, but in conjunction with a host of sensorimotor schemas, it enables the infant not only to interact appropriately with the world but to provide crude descriptions of what is happening in those interactions, descriptions that allow the rudiments of thought to begin.

The spatial relations involved in events, rather than the physical appearance of objects, are conceptually privileged. This probably has to do not only with the nature of newborns' perception but with the fact that what objects do or is done to them is central to our lives and has been so throughout our evolutionary history. We need to know what objects look like to identify them, but that is not what gives them meaning. Instead, two primitives form the bedrock concept of animal. An animal is something that moves by itself and interacts in a contingent way with other things. These descriptions provide the core definition of animal. They are exhaustive definitions in the sense that they are all that the concept consists of at first. If all you know about animals is that they move themselves and interact with other objects, then if they do not, they cannot be animals. No matter that later we make exceptions and learn (and become biased by) prototypes. Adults are the ones whose concepts are typically no longer classical, but complexly radial instead (Lakoff, 1987). Still, the initial core definitions deeply influence adult thought. Ishmael's disquisition on whales in Moby Dick sounds a chord for us all. He knows that whales are mammals and suckle their young, but he discounts that knowledge to insist that they are really fish because they live their entire life in the water and that is what determines their essential nature.

\section{Going Beyond Innate Primitives}

Although I assume the primitives I have listed are innate, in the sense that they are activated by innate attentional proclivities, it is possible that others are learned. This is a potentially controversial issue, because the idea behind primitives has traditionally been not only that they are innate, but that they limit the vocabulary from which concepts can be constructed and are not subject to expansion. But we can certainly question whether this must be the case. The primitives I have discussed are descriptions of innate perceptual biases, but they are produced by a mechanism that continuously redescribes attended perceptual information. Innate saliencies should 
not preclude new spatial analyses when attention demands them. In addition, when language is learned it too can be used to express the results of Perceptual Meaning Analysis. Words can direct attention to and provide labels for previously neglected spatial relations even if there are no innate primitives to apply to them. ${ }^{10}$

However, learning new primitives may not be necessary. Suppose there is a somewhat larger innate set of redescriptions than the 20 or so I have discussed-say, 50. This is hardly a large number, but nevertheless 50 spatial notions may be all that are available even to adults. When one looks at the spatial relations that are expressed in the languages of the world, it appears that our rich perceptual experience of space is conveyed conceptually by a poverty-stricken vocabulary (Mandler, 2004). In English, for example, Landau and Jackendoff (1993) catalogued only about 75 spatial prepositions. About 20 of these are minor variants on each other, such as in and inside, or under, underneath, and beneath, and another set are compounds of two prepositions (between and in between) or extensions such as in back of and backward. ${ }^{11}$ The basic notions expressed seem to be rather less than 50. Of course, other languages package spatial relations in different ways, sometimes using verbs instead of prepositions and/or requiring different information to be expressed in individual words, but it seems that a small set of basic notions is used in all languages and each has a limited vocabulary of spatial terms. Such a limitation may be due to the mechanism of Perceptual Meaning Analysis, which is itself limited in the kinds of redescriptions it produces.

Now you may say that spatial vocabulary does not need to be large because it is only a small part of the human conceptual repertoire. That is true for adults, although spatial notions underlie many abstract ideas, but to this point I have been describing infants' conceptual repertoire, which is limited and based on what they can perceive. One-year-olds do not entertain concepts of truth or justice, and perhaps not even concepts of internal states. Their thought is likely limited to simple descriptions of the events happening around them, but as just discussed, this does not mean the experiences lack richness and individuality. Infants' spatially derived concepts may be limited to things like animal, going in, cause to move, and so forth, but these are associated with well-developed perceptual and motor schemas, so that individuals such as mama (a special animal) and acts such as eating (taking in) are recognized, and accompanying affect is registered as well.

Although spatial descriptions get the conceptual system well started, we must also consider how greater complexity is achieved and truly nonspatial concepts created. There are at least three ways. The first of these I mentioned briefly in the introduction: hypothesizing new information about an existing concept or testing the limits of a conceptual generalization. Because associations accrue to concepts such as animal and not just observed animals, infants are at first prone to conceptual overgeneralizations, such as that all animals drink (Mandler \& McDonough, 1996). Some form of hypothesis and test is implicated in learning that some animals such as fish do not. But, as Fodor (e.g., 1998) emphasized, this kind of inductive learning requires existing concepts, in this case a subset of animals (something like in-water animals) and taking in. In short, hypothesis and test can be used to refine or add 
complexity to already existing concepts, but as Fodor plausibly argued it does not seem possible that it could be used to form concepts in the first place.

A second way of adding complexity is through language. Language directs attention to particulars ('Look there'), helps categorize sensory information for which there are no primitives ('Dogs say woof woof'), and provides labels for established perceptual schemas ('That's a doggie'). For example, the fact that different-looking self-moving interactors are given different labels by the community must focus attention on their differences. The infant listening to a parent reading a picture book may conceptualize animal when seeing a dog, but the parent consistently says, 'Look at the doggie. What does the doggie say? It says "woof woof". The infant has already perceptually categorized dogs as different in appearance (and probably sound) from various other animals, but still has work to do-he or she must associate the new label with this visual-auditory schema.

I do not want to make light of the mystery of infants' understanding that words refer, but that is a different issue from concept acquisition. Because infants do learn that words point to things, they can attach a label to an object they already recognize and that they know is an animal. ${ }^{12}$ A new concept (which is a subdivision of an old one) is on its way. Dog is an animal of a certain appearance, called 'dog', and makes sounds called 'woof woof. Conceptual differentiation is not an easy task, of course. The phenomenon of overextension of nouns (Clark, 1983), in which a word like 'dog' is used in both comprehension and production for a variety of animals as late as 2 years (McDonough, 2002) is one of the signs (along with free substitution of one for another when imitating) that conceptual distinctions between dogs and other land animals are hard won.

A third source of new concepts, especially useful for constructing abstract concepts, is the analogical or metaphorical extension of spatially-based concepts into nonspatial realms. We know that a great many adult concepts are constructed from such extensions (e.g., Gentner, 1983), and analogical learning is evident even in 10month-old infants (Chen, Sanchez, \& Campbell, 1997). For example, the spatial nature of the concept of time has long been acknowledged by linguists and psychologists (Clark, 1973; Guyau, 1890). As Guyau put it 120 years ago, 'We can easily imagine space; we have an inner eye for it, an intuition. Try, on the other hand, to represent time as such; you will only succeed by means of a representation of space'. We conceptualize time as a linear path and in all languages studied temporal terms have a spatial sense as their primary meaning (Fillmore, 1982; Traugott, 1978). Of course, we have the intuition that we can tell the difference between a spatial path and a temporal one, but that is because of differences in perceptual experience, not in conceptualization. We live through time, we can sense time passing as we engage in events, but that temporal experience per se is not conceptual. When we try to think about it or describe it, we revert to spatial metaphor-and short times, passage of time, time lines, time approaching-all of our descriptions are spatial. We do have a concept of time, but it is a spatial concept pointing to a certain kind of bodily experience. This is another example not only of the way in which spatial relations are 
fundamental to our conceptual system but how some concepts require supplementation by sensorimotor schemas.

There are many other examples of abstract concepts being derived from bodily experiences in conjunction with spatial primitives. I believe force is one of these. As discussed earlier, perception of transfer of motion from one object to another underlies this concept, along with associated bodily experiences of forces. Although many researchers working on conceptualization within an embodiment framework assume there are FORCE image-schemas (Johnson, 1987; Peña Cervel, 2003), our concept of force may depend on spatial image-schemas in a way similar to that of time. A spatial representation of motion being transferred into an object becomes coupled with bodily experiences of pressure or force. The redescription is a kinetic spatial one, with the sensorimotor part adding a crude dynamic notion (people seem to be rather poor at representing dynamics; Proffitt \& Bertenthal, 1990).

These are just two examples that illustrate how a spatially-derived conceptual base applied to perceptual and motor schemas can generate abstract concepts. There are many more, such as our concept of comprehension as grasping or taking in and more itself as going up. Indeed, it has been claimed that all abstract inferences are metaphorical versions of spatial inferences inherent in the topological structure of image-schemas (Lakoff, 1990). As long as we consider metaphors as a minor peculiarity of language, we will not understand their pivotal importance in understanding human thought. We have not paid enough serious attention to embodiment-how sensorimotor experiences combined with a spatial vocabulary can create a more powerful conceptual system than would be possible with the vocabulary alone. The infant's repertoire of spatial primitives may not seem to get us very far into the adult conceptual system, but combined with humans' pervasive analogical use of one domain to understand others (e.g., Gentner, 1983), we can see that spatial primitives do not have to do all the work alone. Concepts can consist in part of unconceptualized sensorimotor information. This seeming oxymoron expresses that some concepts consist of a spatial description pointing to a sensorimotor experience.

\section{Conclusions}

What can we conclude about concept acquisition from this excursion into infancy? I have shown how a conceptual system can get started from a handful of innate primitives that describe spatial relations and motions in space. This requires a mechanism that redescribes sensorimotor information in terms of these primitives but does not operate by hypothesis and test. I have only taken the infant up to sometime between a year and 18 months, but by this time there is in place the kind of analogical learning that allows spatial notions to be used to structure nonspatial domains.

It is also the time when language begins in earnest. The primitives I have described not only formulate a number of major conceptual domains and are available for 


\section{J. M. Mandler}

applying to nonspatial domains, they also create a sufficient conceptual base to get language started (Mandler, 2004). Once language takes off, it provides a device for the community to teach the details that are needed to formulate concepts that in daily life need to be specified more exactly than animal or container (see, for example, Gershkoff-Stowe \& Smith, 2004). Language becomes a powerful adjunct to Perceptual Meaning Analysis, because it focuses the infant's attention on specific perceptual details and provides labels that categorize them if the infant has not done so already (Waxman \& Markow, 1993). This is why 'woof woof' is an important word-it labels a sound the infant has learned to recognize and associate with animals of a particular appearance. The sound does not need to be analyzed further - the label acts as a pointer to the sound that gets added to the concept.

This is where Fodor's view of concept formation falls short. He assumes that the perceptual world, if it is to be useful for concept formation is necessarily taken in under a conceptual description. In the discussion following my talk at the 2005 Cognitive Science symposium 'Solutions to Fodor's Puzzle of Concept Acquisition', we used as an example of differentiating the concept animal, barking and nonbarking animals. As put in the transcript of his comments, he said:

Start with the notion of ANIMAL, which you get from somewhere. You differentiate it into the ones that bark and the ones that don't, and you say dogs bark and cats do something else, so dogs are not cats. How is this going to work? In particular, how are you going to achieve that differentiation, unless you already have the notion ANIMAL (well that's granted) but also the notion BARKS. What you have to do, is to learn the following thing: ... animals are differentiated into things that bark and things that don't bark. Unless you have the concept dog, unless you have the concept bark, you can't state the concept-you can't present to your mind the differentiating hypothesis unless you have the concepts that constitute the hypothesis. That I think is a self evident truth. (Cognitive Science Symposium, July 2005)

Such a formulation underestimates the other side of information processing-the side that can produce perceptual categorization and other sensorimotor schemas in the absence of conceptual description. Infants learn to recognize the sound of dogs barking, but initially there is no conceptual description applied to it.

In clear contrast to this view, Fodor expanded his argument by saying that 'to get the datum that dogs bark... you have to observe it under the description "is barking" [...] You can't see things as barking unless you have the concept barking' (Cognitive Science Symposium, July 2005). But that's not quite right. A bark is a sound-experience, not a concept. You can attend to the sound without a conceptual description, and a label can be applied to the sound you are attending-indeed that may be all we ever do with something like barking, for which there are no spatial primitives. You can attend to the 'umph' you feel when hitting or pushing against something immoveable. This 'umph' becomes associated with the conceptual description of BLOCKED PATH, so that one activates the other. In short, a conceptual description can be augmented by a feeling that is not itself conceptually described. It has become a package that, to use Fodor's terminology, can be 
'presented to the mind', and one that at some point will become labeled by language as 'force'. The label acts as a shorthand for the concept that we use when we think. It is, of course, a characteristic of adult thought to use language as a shorthand to point to concepts without unpacking them.

Needless to say, the thought of one-year-olds is apt to be crude, not just because they don't know lots of things adults know, but because their conceptual repertoire to express what they do know is extremely limited. At the same time, I believe that the formulation I have offered changes the ground rules for understanding concept formation. Instead of starting with primitives like brown or leggedness or bark, conceptualization begins on an entirely different level: namely, a redescription of the events in which objects take part, using abstract spatial primitives. Infants watch objects move around and interact in various ways and conceptualize the objects and the events themselves in spatial terms-in the case of dogs, something like 'selfstarting interactors'.

In summary, this account of concept acquisition challenges some commonly held views in several ways. First, many concepts are not acquired by hypothesis and test, but by an analytic descriptive mechanism. Hypothesis and test, in contrast, are part of an inductive process that constitutes one of the ways existing concepts become expanded, or to determine whether newly encountered instances are exemplars of an existing concept. Second, the primitives that enter into concept formation are neither traditionally conceived sensory attributes such as red, nor are they unstructured. Primitive here does not mean simple or unstructured, but means foundational, first, ur, or whatever term you want to describe the innate vocabulary that gets concept formation started. These primitives are spatial notions. There are not a great many of them, but they are sufficient to give foundational descriptions for the major classes of objects and relations, and although less studied in infancy, almost certainly many kinds of actions that humans perform.

Third, it is not the case that to observe something like barking one must do so under a conceptual description. A good deal of information is subject to innate conceptual description, but other kinds of information, such as sounds, colors, bodily feelings, and complex shapes are not; they are observed and may be categorized but are not at first conceptualized. Language is useful to the process of linking conceptual descriptions to these unanalyzed sensorimotor experiences. However, language is not always required. As discussed earlier, a preverbal conceptual description such as MOTION TRANSFER can become associated with and point to a bodily feeling of the pressure involved in being pushed or pushing. What results is a unique combination and one can learn a label for it (albeit sometimes with difficulty and even idiosyncratically).

Fourth, Fodor came to the conclusion that there cannot be enough innate primitives to account adequately for concept creation. Bowerman (1996) made a similar claim vis-à-vis language acquisition, suggesting that so many image-schema primitives would be required to account for the different ways that languages package containment and other notions as to make them ineffective in explaining acquisition. I have tried to show that such views are mistaken (Mandler, 2004). There are 


\section{J. M. Mandler}

certainly enough spatial primitives to create the major classes of object and relational concepts that get the conceptual system started and enable early language. These global concepts, often prodded by adults' more detailed language, become subdivided through further Perceptual Meaning Analysis and associative learning into the many object and relational concepts used in daily life. These concepts are supplemented in turn by the ability to extend the descriptions provided by the innate spatial primitives to nonspatial domains and then to attach labels to these extensions. Adult concepts are thoroughly saturated with such metaphors.

It may seem ironic that spatial descriptions need first to become uncoupled from sensorimotor representations to allow conceptual thought, yet gain power by becoming re-associated with them. The initial descriptions allow the formation of a conceptual system, which of course is vitally important. However, the ability of these descriptions to be linked to bodily feelings, and, often with the help of language, to nonspatial percepts, greatly expands the system. It is not a contradiction in terms to say that human concepts in some sense include nonconceptualized information. But neither is that a license for the commonly held view that concepts and percepts are merely end points of a continuum. They are distinct processes in human intellectual functioning that interact, but the interaction does not make them the same.

\section{Acknowledgement}

This article is based on a paper given at the 2005 Cognitive Science Society annual meeting in a symposium entitled 'Solutions to Fodor's Puzzle of Concept Acquisition'. I thank Adele Abrahamsen, William Bechtel, and Daniel Weiskopf for helpful comments on an earlier version and David Kirsh and George Mandler for interesting discussion on the issues.

\section{Notes}

[1] The term 'basic-level' has never been given a satisfactory definition, but is usually used to refer to the level at which familiar mammals, household objects, vehicles, and sometimes plants are commonly labeled-hence, dog, cup, car, tree; see Mandler $(1998,2004)$ for discussion. The belief that such concepts are the first to be formed has generated a number of mistaken conclusions about early concept formation, for example, Fodor (1980, p. 311).

[2] These results are not merely due to differences in inter- and intra-domain perceptual similarity; e.g., 9-month-olds categorize birds and airplanes as different in spite of great similarity of the models used to test them (Mandler \& McDonough, 1993). This finding can be contrasted with their failure to categorize dogs and fish as different, in spite of their different physical appearance.

[3] I am not discussing 'true' or 'expert' definitions, rather the properties of classes that hold in our experience and that we think of as necessary, whether or not that is the case-in short, the concepts infants and other laymen think with. No reference to experts is needed to understand concepts.

[4] Conceptual primitives should be considered foundational or developmental primitives rather than traditional semantic primitives (see Carey, 1982 and Mandler, 2004). 
[5] For infants, the relevant distinction is almost certainly animal versus nonanimal rather than animate versus inanimate. Including plants with animals in a common animate domain is a late, verbally taught acquisition (Carey, 1985), and may not occur at all.

[6] Differentiating kinds within domains may occur in more than one way. Some subdivisions can be made by combining primitives (e.g., land or 'surface' animals and air or 'up' animals), which is the approach of the Rogers and McClelland model. However, other subdivisions (e.g., various mammal kinds) may take place by associating unanalyzed perceptual appearances with conceptual descriptions. This issue is discussed later.

[7] Although plants sometimes exhibit motion, \pm PATH seems more important in this case than \pm MOTION.

[8] Current data suggest that support is not as straightforward a concept as containment (Casasola \& Cohen, 2002; Choi, 2006), although this might be because attachment and support have not been separately studied.

[9] Indoor things, outdoor things, taking in, and behind are given question marks because the evidence collected so far is indirect.

[10] And of course, language can be used to teach metric and adventitious spatial relations such as 'six feet tall' or 'slanted backward'.

[11] Some of the apparent synonyms in English may be due to the two different linguistic streams-Romance and Germanic - that formed the modern language.

[12] Of course, they also learn that words refer to actions, and there is evidence that spatial image-schemas are used in everyday verb understanding (Richardson, Spivey, Barsalou, \& McRae, 2003)

\section{References}

Aguiar, A., \& Bailargeon, R. (1998). Eight-and-a-half-month-old infants' reasoning about containment events. Child Development, 69, 636-653.

Arterberry, M. E., \& Bornstein, M. H. (2001). Three-month-old infants' categorization of animals and vehicles based on static and dynamic attributes. Journal of Experimental Child Psychology, $80,333-346$.

Arterberry, M. E., Craton, L. G., \& Yonas, A. (1993). Infants' sensitivity to motion-carried information for depth and object properties. In C. E. Granrud (Ed.), Visual perception and cognition in infancy. Hillsdale, NJ: Erlbaum.

Bahrick, L. E., Gogate, L. J., \& Ruiz, I. (2002). Attention and memory for faces and actions in infancy: The salience of actions over faces in dynamic events. Child Development, 73, 1629-1643.

Baillargeon, R. (1986). Representing the existence and the location of hidden objects: Object permanence in 6- and 8-month-old infants. Cognition, 23, 21-41.

Baillargeon, R., Kotovsky, L., \& Needham, A. (1995). The acquisition of physical knowledge in infancy. In D. Sperber, D. Premack, \& A. J. Premack (Eds.), Causal cognition. New York: Oxford University Press.

Baillargeon, R., \& Wang, S. (2002). Event categorization in infancy. Trends in Cognitive Science, 6, 85-93.

Bar, M., \& Biederman, I. (1998). Subliminal visual priming. Psychological Science, 9, 464-469.

Barsalou, L. W. (1999). Perceptual symbol systems. Behavioral and Brain Sciences, 22, 577-660.

Behl-Chadha, G. (1996). Superordinate-like categorical representations in early infancy. Cognition, $60,105-141$.

Bowerman, M. (1996). Learning how to structure space for language: A crosslinguistic perspective. In P. Bloom, M. A. Peterson, L. Nadel, \& M. F. Garrett (Eds.), Language and space. Cambridge, MA: MIT Press. 


\section{J. M. Mandler}

Carey, S. (1982). Semantic development: The state of the art. In E. Wanner \& L. R. Gleitman (Eds.), Language acquisition: the state of the art. Cambridge: Cambridge University Press.

Carey, S. (1985). Conceptual change in childhood. Cambridge, MA: MIT Press.

Casasola, M., \& Cohen, L. B. (2002). Infant spatial categorization of containment, support, or tightfit spatial relations. Developmental Science, 5, 247-264.

Chen, Z., Sanchez, R. P., \& Campbell, T. (1997). From beyond to within their grasp: The rudiments of analogical problem-solving in 10- and 13-month-olds. Developmental Psychology, 33, $790-801$.

Choi, S. (2006). Preverbal spatial cognition and language-specific input: Categories of containment and support. In K. Hirsh-Pasek \& R. M. Golinkoff (Eds.), Action meets word: How children learn verbs. New York: Oxford University Press.

Clark, E. V. (1983). Concepts and words. In J. H. Flavell \& E. M. Markman (Eds.), Cognitive development: Vol. 3, of P. H. Mussen (Series Ed.), Handbook of child psychology. New York: Wiley.

Clark, H. H. (1973). Space, time, semantics, and the child. In T. E. Moore (Ed.), Cognitive development and the acquisition of language. San Diego: Academic Press.

Cleary, A. M., \& Greene, R. L. (2005). Recognition without perceptual identification: A measure of familiarity? Quarterly Journal of Experimental Psychology, 58A, 1143-1152.

Csibra, G., Bíró, S., Koós, O., \& Gergely, G. (2003). One-year-old infants use teleological representations of actions productively. Cognitive Science, 27, 111-133.

Csibra, G., Gergely, G., Bíró, S., Koós, O., \& Brockbank, M. (1999). Goal attribution without agency cues: The perception of 'pure reason' in infancy. Cognition, 72, 237-267.

Fagan, J. F. III, \& Singer, L. T. (1979). The role of simple feature differences in infant recognition of faces. Infant Behavior and Development, 2, 39-46.

Fauconnier, G. (1994). Mental spaces. Cambridge, MA: MIT Press.

Fauconnier, G., \& Turner, M. (2002). The way we think. New York: Basic Books.

Fillmore, C. (1982). Toward a descriptive framework for spatial deixis. In R. J. Jarvella \& W. Klein (Eds.), Speech, place, and action psychology. New York: Wiley.

Fodor, J. A. (1975). The language of thought. New York: Crowell.

Fodor, J. (1980). The present status of the innateness controversy. In J. Fodor (Ed.), Representations: Philosophical essays on the foundations of cognitive science. Cambridge, MA: MIT Press.

Fodor, J. A. (1998). Concepts: Where cognitive science went wrong. New York: Oxford University Press.

Frye, D., Rawling, P., Moore, C., \& Myers, I. (1983). Object-person discrimination and communication at 3 and 10 months. Developmental Psychology, 19, 303-309.

Gentner, D. (1983). Structure-mapping: A theoretical framework for analogy. Cognitive Science, 7, 155-170.

Gergely, G., Nádasdy, Z., Csibra, G., \& Bíró, S. (1995). Taking the intentional stance at 12 months of age. Cognition, 56, 165-193.

Gershkoff-Stowe, L., \& Smith, L. B. (2004). Shape and the first hundred nouns. Child Development, $75,1098-1114$.

Guyau, J.-M. (1988/1890). The origin of the idea of time. Reprinted in J. A. Michon, V. Pouthas, \& J. L. Jackson (Eds.), Guyau and the idea of time. Amsterdam, Netherlands: North-Holland.

Hespos, S. J., \& Baillargeon, R. (2001a). Reasoning about containment events in very young infants. Cognition, 78, 207-245.

Hespos, S. J., \& Baillargeon, R. (2001b). Infants' knowledge about occlusion and containment events: A surprising discrepancy. Psychological Science, 12, 141-147.

Hodges, J. R., Graham, N., \& Patterson, K. (1995). Charting the progression of semantic dementia: Implications for the organisation of semantic memory. Memory, 3, 463-495.

Johnson, M. (1987). The body in the mind: The bodily basis of meaning, imagination, and reason. Chicago: University of Chicago Press. 
Keil, F. C. (1998). Cognitive science and the origins of thought and knowledge. In R. M. Lerner (Ed.), Theoretical models of human development: Vol. 1 of W. Damon (Series Ed.), Handbook of child psychology. New York: Wiley.

Kellman, P. J. (1993). Kinematic foundations of infant visual perception. In C. E. Granrud (Ed.), Visual perception and cognition in infancy. Hillsdale, NJ: Erlbaum.

Lakoff, G. (1987). Women, fire, and dangerous things: What categories reveal about the mind. Chicago: University of Chicago Press.

Lakoff, G. (1990). The invariance hypothesis: is abstract reason based on image-schemas? Cognitive Linguistics, 1, 39-74.

Landau, B., \& Jackendoff, R. (1993). "What" and "where" in spatial language and spatial cognition. Behavior and Brain Sciences, 16, 217-265.

Laurence, S., \& Margolis, E. (2002). Radical concept nativism. Cognition, 86, 25-55.

Leslie, A. M. (1982). The perception of causality in infants. Perception, 11, 173-186.

Leslie, A. M. (1984). Infant perception of a manual pick-up event. British Journal of Developmental Psychology, 2, 19-32.

Mandler, G., Nakamura, Y., \& van Zandt, B. J. (1987). Nonspecific effects of exposure on stimuli that cannot be recognized. Journal of Experimental Psychology: Learning, Memory, \& Cognition, $13,646-648$.

Mandler, J. M. (1992). How to build a baby II: Conceptual primitives. Psychological Review, 99, 587-604.

Mandler, J. M. (1998). Representation. In D. Kuhn \& R. Siegler (Eds.), Cognition, perception, and language: Vol. 2 of W. Damon (Series Ed.), Handbook of child psychology. New York: Wiley.

Mandler, J. M. (2004). The foundations of mind: Origins of conceptual thought. New York: Oxford University Press.

Mandler, J. M. (2007). The conceptual foundations of animals and artifacts. In E. Margolis \& S. Laurence (Eds.), Creations of the mind: Theories of artifacts and their representation. Oxford: Oxford University Press.

Mandler, J. M., \& McDonough, L. (1993). Concept formation in infancy. Cognitive Development, 8, 291-318.

Mandler, J. M., \& McDonough, L. (1996). Drinking and driving don't mix: Inductive generalization in infancy. Cognition, 59, 307-335.

Mandler, J. M., \& McDonough, L. (1998a). On developing a knowledge base in infancy. Developmental Psychology, 34, 1274-1288.

Mandler, J. M., \& McDonough, L. (1998b). Studies in inductive inference in infancy. Cognitive Psychology, 37, 60-96.

Mandler, J. M., \& McDonough, L. (2000). Advancing downward to the basic level. Journal of Cognition and Development, 1, 379-404.

McDonough, L. (2002). Basic-level nouns: First learned but misunderstood. Journal of Child Language, 29, 357-377.

McDonough, L., Choi, S., \& Mandler, J. M. (2003). Understanding spatial relations: Flexible infants, lexical adults. Cognitive Psychology, 46, 229-259.

Michotte, A. E. (1963). The perception of causality. London: Methuen.

Murray, A. D., \& Trevarthen, C. (1985). Emotional regulation of interactions between twomonth-olds and their mothers. In T. M. Field \& N. A. Fox (Eds.), Social perception in infants. Norwood, NJ: Ablex.

Pauen, S. (2000). The "animal-ball experiment": A new paradigm to study causal attribution of animate motion in infancy. Poster presented at the International Society of Infant Studies, Brighton, England.

Peña Cervel, M. S. (2003). Topology and cognition: What image-schemas reveal about the metaphorical language of emotions. Munich: LINCOM. 


\section{J. M. Mandler}

Poulin-Dubois, D., Lepage, A., \& Ferland, D. (1996). Infants' concept of animacy. Cognitive Development, 11, 19-36.

Proffitt, D. R., \& Bertenthal, B. I. (1990). Converging operations revisited: Assessing what infants perceive using discrimination measures. Perception \& Psychophysics, 47, 1-11.

Quinn, P. C. (2003). Concepts are not just for objects: Categorization of spatial relation information by infants. In D. R. Rakison \& L. M. Oakes (Eds.), Early category and concept development. New York: Oxford University Press.

Quinn, P. C., Adams, A., Kennedy, E., Shettler, L., \& Wasnik, A. (2003). Development of an abstract category representation for the spatial relation between in 6- to 10-month-old infants. Developmental Psychology, 39, 151-163.

Quinn, P. C., Eimas, P. D., \& Rosenkrantz, S. L. (1993). Evidence for representations of perceptually similar natural categories by 3 -month-old and 4-month-old infants. Perception, 22, 463-475.

Richardson, D., Spivey, M., Barsalou, L., \& McRae, K. (2003). Spatial representations activated during real-time comprehension of verbs. Cognitive Science, 27, 767-780.

Roberson, D., Davidoff, J., Davies, I. R. L., \& Shapiro, L. R. (2005). Color categories: Evidence for the cultural relativity hypothesis. Cognitive Psychology, 50, 378-411.

Rogers, T. T., \& McClelland, J. L. (2004). Semantic cognition: A parallel distributed processing approach. Cambridge, MA: MIT Press.

Sodian, B., Schoeppner, B., \& Metz, U. (2004). Do infants apply the principle of rational action to human agents? Infant Behavior and Development, 27, 31-41.

Spelke, E. S., Philips, A., \& Woodward, A. L. (1995). Infants' knowledge of object motion and human action. In D. Sperber, D. Premack, \& A. J. Premack (Eds.), Causal cognition. Oxford Symposium at the annual meeting of the Cognitive Science Society, Stresa, Italy, July 2005: Clarendon Press.

Traugott, E. C. (1978). On the expression of spatio-temporal relations in language. In J. H. Greenberg (Ed.), Universals of human language: Vol. 3. Word structure. Stanford, CA: Stanford University Press.

Ware, E. A., Uttal, D. H., Wetter, E. K., \& DeLoache, J. S. (2006). Young children make scale errors when playing with dolls. Developmental Science, 9, 40-45.

Watson, J. (1972). Smiling, cooing, and 'the game'. Merrill-Palmer Quarterly, 18, 323-340.

Waxman, S. R., \& Markow, D. B. (1995). Words as invitations to form categories: Evidence from 12- to 13-month-old infants. Cognitive Psychology, 29, 257-302.

White, P. A. (1988). Causal processing: Origins and development. Psychological Bulletin, 104, 36-52.

Woodward, A. L. (1998). Infants selectively encode the goal object of an actor's reach. Cognition, 69, $1-34$.

Woodward, A. L. (1999). Infants' ability to distinguish between purposeful and non-purposeful behaviors. Infant Behavior and Development, 22, 145-160. 